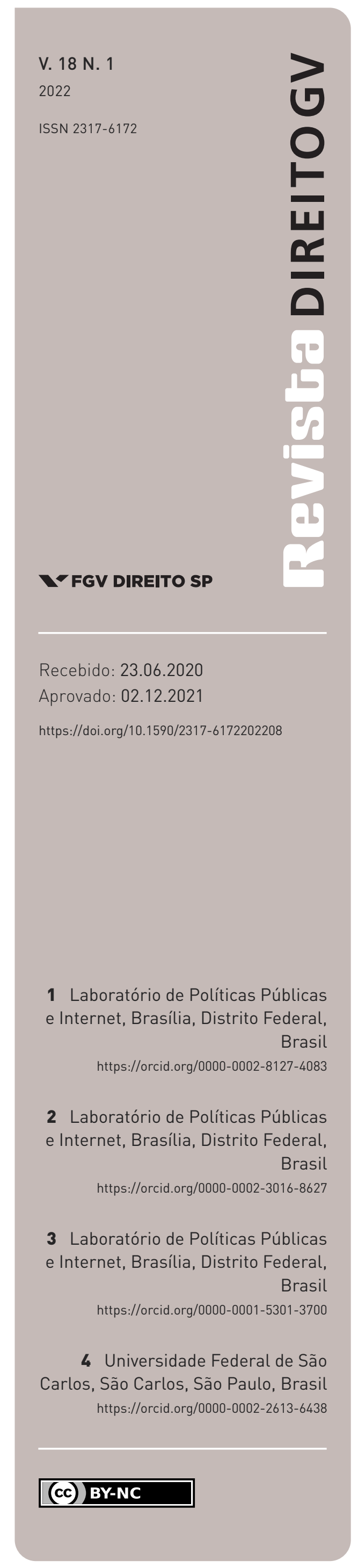

\title{
Nomes de domínio e propriedade intelectual: reflexões sobre resolução de controvérsias a partir da Análise Econômica do Direito
}

DOMAIN NAMES AND INTELLECTUAL PROPERTY: LAW AND ECONOMICS REFLECTIONS ON DISPUTE SETTLEMENT

\author{
Carla Frade de Paula Castro', Davi Antonio Araújo Silva², Gabriel \\ Araújo Souto ${ }^{3}$ e Nayara F. Macedo de Medeiros Albrecht ${ }^{4}$
}

\section{Resumo}

O cybersquatting consiste no registro de má-fé de um nome de domínio contendo marca de terceiro, com intuito de posterior revenda ao seu legítimo titular. A fim de coibir essa prática nociva, a Corporação da Internet para Atribuição de Nomes e Números (ICANN) criou um sistema de resolução de controvérsias bem difundido, mas rejeitado pelo Brasil dadas as peculiaridades de seus litígios. Este artigo analisa, sob a perspectiva da Análise Econômica do Direito, a eficiência do Sistema Administrativo de Conflitos de Internet (SACl-Adm), contrastando-a com a do Superior Tribunal de Justiça (STJ). Notou-se uma clara preferência pelo primeiro, com 297 decisões, as quais repetem o viés pró-reclamante verificado no sistema da ICANN. Já os seis casos do STJ revelam uma jurisprudência uniforme, centrada em torno de quatro teses principais. Nestas, a filosofia utilitarista que justifica a proteção às marcas aparece apenas de forma marginal, preferindo o Tribunal investigar a existência de má-fé do proprietário do domínio, em clara alusão à dimensão moral da Justiça, não obstante os efeitos econômicos da prática de cybersquatting. Conclui-se que o SACl-Adm é o sistema mais efetivo, dados os seus menores custos, a média de 40 dias para tomada da decisão e o baixo índice de judicialização.

\section{Palavras-chave}

Cybersquatting; marcas; SACI-Adm; Superior Tribunal de Justiça; Análise Econômica do Direito.

\section{Abstract}

Cybersquatting is the registration in bad faith of a domain name containing a third party's trademark to later resell it to its legitimate holder. In order to curb this harmful practice, the Internet Corporation for Assigned Names and Numbers (ICANN) created a widespread dispute settlement system, which Brazil has rejected due to the peculiarities of its disputes. Based upon a Law and Economics perspective, this paper analyzes the efficiency of the Internet Conflict Administrative System (SACl-Adm) in comparison with that of the Superior Court of Justice (STJ). We found a clear preference for the former, which has issued 297 decisions that repeat the pro-complainant bias seen in the ICANN system. The six STJ cases, on the other hand, reveal a uniform jurisprudence centered around four main theses. The utilitarian philosophy underlying trademark protection appears only marginally in these decisions, as the Court prefers to investigate the bad faith of the domain owner emphasizing the moral dimension of Justice, despite the economic effects of cybersquatting. We conclude that SACl-Adm is the most effective system, given its lower costs, its quick decisions (40-days average), and its low judicialization rates.

\section{Keywords}

Cybersquatting; trademarks; SACl-Adm; Superior Court of Justice; Law and Economics. 


\section{INTRODUÇÃO}

A expansão da internet e de outras tecnologias gerou desafios à proteção da propriedade intelectual (PI), tendo em vista a velocidade com que os bens imateriais são reproduzidos, apropriados e compartilhados no meio digital (FISHER, 2004). Não por acaso, diversos temas relacionados à PI fazem parte dos estudos jurídicos sobre a relação entre tecnologia e sociedade, tais como inteligência artificial, proteção de dados pessoais e nomes de domínio. Tais temas referem-se a questões relevantes ao cenário internacional, uma vez que a internet "não tem fronteiras", pois consiste em um veículo de difusão simultânea e multirregional de conteúdos diversos.

O presente artigo visa explorar o último desses temas ao discutir os mecanismos de resolução de conflitos no que tange à prática conhecida como cybersquatting. Oriunda da língua inglesa, a palavra cybersquatting é utilizada para designar a apropriação de um nome de domínio mediante registro feito de má-fé (KING, 2000). Isso pode acontecer tanto por meio do registro de um nome igual ao de uma marca conhecida, com o objetivo de revender o domínio, quanto pelo registro de nomes similares com pequenos erros de digitação (KING, 2000; GILWIT, 2003; CURTIN, 2010). O último caso recebe o nome de typosquatting (GILWIT, 2003). A legislação estadunidense concede o direito aos detentores de marca de processar quem utiliza um nome de domínio que seja idêntico ou similar ao de uma marca distintiva ou famosa (EUA, 2020, seção 1.125(d)).

No Brasil, não há disposição a esse respeito, o que torna a relação entre os nomes de domínio e as leis de propriedade intelectual bastante controversa. Se, por um lado, o domínio não precisa guardar relação direta com o conteúdo do site, por outro, costuma tratar-se de um indicativo do produto ou serviço veiculado, o que está relacionado à proteção de marcas (KING, 2000; CURTIN, 2010). Como resultado, vemos um grande número de titulares de marcas acionando mecanismos de resolução de controvérsias na esperança de reverter para si aqueles domínios que façam referência às suas marcas, mas que estejam registrados em nome de terceiros.

O objetivo deste artigo é apresentar os mecanismos de resolução de controvérsias relativos à infração de marca no âmbito do ato de cybersquatting e, também, propor uma reflexão acerca da sua eficiência no combate a tal violação. Para tanto, consideram-se como parâmetros de eficiência os custos dos procedimentos, o tempo para a tomada da decisão e sua posterior judicialização. A metodologia empregada combina a revisão da literatura pertinente à análise quantitativa de casos enfrentados no âmbito do Sistema Administrativo de Conflitos de Internet (SACI-Adm) e do Superior Tribunal de Justiça (STJ); para os casos do STJ, é feita ainda uma análise qualitativa das decisões buscando entender os principais argumentos utilizados pelos magistrados para embasar suas conclusões. Trata-se de uma abordagem comparativa na medida em que são discutidas as diferenças e semelhanças em relação aos procedimentos e às teses estabelecidas. Recorre-se à estatística descritiva na apresentação dos dados. 
O artigo aborda, portanto, dois grandes temas: i) a relação entre cybersquatting e propriedade intelectual; e ii) as perspectivas expressas na resolução de conflitos nessa seara por meio da Análise Econômica do Direito (AED). Para o primeiro, apresentamos os principais conceitos envolvidos na discussão, ligados às áreas dos nomes de domínio e da propriedade intelectual. Para o segundo, apresentamos os principais mecanismos de resolução de conflitos disponíveis, assim como as críticas que lhes são feitas pela literatura especializada; por fim, comparamos tais mecanismos de modo a analisar as teses predominantes e a eficiência da resolução de controvérsias.

$\mathrm{O}$ recorte do artigo remete às disputas referentes às relações econômicas e comerciais, que envolvem, sobretudo, discussões sobre proteção de marcas e concorrência desleal. O marco teórico utilizado é a Teoria Econômica do Direito e as justificativas utilitaristas da propriedade intelectual. Em um primeiro momento, utilizamos as premissas da Teoria Econômica do Direito para explicar a adoção e a eficiência de mecanismos de resolução de conflitos. Em um segundo, avalia-se em que medida tais teorias são aplicadas nas decisões das cortes no âmbito das resoluções de conflitos envolvendo nomes de domínio.

\section{i. Propriedade intelectual, domínios e cybersquatting}

\section{I. NOMES DE DOMÍNIO E CYBERSQUATTING}

$\mathrm{Na}$ internet, computadores e serviços podem ser identificados de diversas maneiras e a partir de diferentes protocolos, que têm funções específicas no estabelecimento da comunicação. O protocolo IP (Internet Protocol) é particularmente importante, pois oferece uma numeração para identificar de forma única tais recursos (KRUGER, 2015, p. 5). A numeração IP, porém, não é intuitiva para a grande maioria dos usuários, já que é composta por uma sequência única de dígitos de 32 ou 128 bits.

Com o desenvolvimento da World Wide Web e a possibilidade de navegar dinamicamente em conteúdos hospedados em redes distintas, foi necessário também que se criassem dispositivos para tornar a experiência mais amigável para usuários leigos em tecnologia, especialmente na identificação dos diferentes recursos à disposição (ICANN, 2010, p. 3). Como os endereços IP são difíceis de lembrar, o Domain Name System (DNS) permite sua substituição por uma série de letras ou uma combinação de letras e números (nome de domínio), facilitando muito para os usuários da internet a lembrança de sites e endereços de e-mail (ICANN, 2010, p. 3). Em outras palavras, os nomes de domínio fornecem aos usuários um nome de local simples em vez de exigir que eles usem uma longa lista de números.

No início, todos os nomes de domínio eram registrados em um arquivo chamado "HOSTS. TXT”, mantido pelo Stanford Research Institute - Network Information Center (SRI-NIC), responsável por receber modificações dos administradores participantes e repassar o arquivo atualizado com a ligação entre nomes que identificavam os recursos e seus respectivos 
endereços IP. Com a popularização do uso da internet, isso ficou impraticável: houve um aumento abrupto da quantidade de participantes da rede e, por questões de tráfego, colisão de nomes e consistência da rede, foi necessário criar alguma solução que permitisse o gerenciamento descentralizado e automatizado da divulgação de nomes e recursos, o que deu origem ao Sistema de Nomes de Domínio (DNS, para Domain Name System) tal como se conhece hoje (TANENBAUM, 2007).

Há três usos comuns para a mesma sigla: o sistema DNS (Domain Name System) está vinculado ao serviço DNS (Domain Name Service), que é prestado por servidores DNS (Domain Name Server) ao redor do mundo. Esses servidores estão organizados de maneira hierárquica e trocam atualizações entre si de maneira automática, cada um mantendo seu próprio banco de dados com os recursos disponíveis em determinado domínio.

Os registros de recursos são linhas nesses bancos de dados que contêm informações como o endereço ou nome do domínio a que aquele recurso se aplica, seu tempo de validade e o tipo de recurso disponível. Em redes privadas, os administradores de rede definem o que está disponível dentro de um domínio. Na internet, é necessário que os domínios sejam organizados de maneira mais cuidadosa.

De maneira geral, um nome de domínio é o que existe entre o sinal de protocolo (http://) e a primeira barra em um URL ou endereço da Web. Ele se estrutura em três partes, que se distinguem por sua hierarquia: ([domínios de terceiro nível].[domínios de segundo nível].[domínios de nível superior $\left.{ }^{1}\right]$ ) ou, por exemplo, “www.google.com”. Dentro da hierarquia DNS, os domínios de terceiro nível, geralmente chamados de subdomínio, seguem naturalmente os domínios de segundo nível, que ficam localizados à sua direita. Por exemplo, “www" é o domínio de terceiro nível mais conhecido. Se uma empresa usa vários domínios de terceiro nível, geralmente refere-se a um servidor específico dentro da empresa (CRABB, 2018).

Por sua vez, os domínios de segundo nível seguem os domínios de nível superior. Por exemplo, no “www.google.com.br”, a palavra "google” é o domínio de segundo nível do domínio de nível superior “.com”. Com frequência, os domínios de segundo nível são o nome da

1 Atualmente, existem 20 domínios genéricos de nível superior (gTLDs) na zona raiz, que é o nível mais alto da estrutura do sistema de nomes de domínio. Embora existam mais de 1.500 gTLDs em uso, esses 21 constituem a grande maioria de todos os tipos de nomes de domínio (CRABB, 2018). Eles formam quatro subcategorias: (i) domínios genéricos que podem ser usados para fins gerais (.com, .net, .org, .info); (ii) domínios restritos genéricos que podem ser usados apenas para fins específicos (.pro, .biz e .name); (iii) domínios patrocinados que só podem ser usados por empresas envolvidas especificamente com esse setor (.edu, .gov, .int, .mil, .aero, .cat, .asia, .mobi, .coop, .travel, .tel e .jobs); e (iv) infraestrutura (.arpa), que era um dos domínios de nível superior originais usados para ajudar na infraestrutura de DNS (CRABB, 2018). 
empresa ou fornecedor que registrou o nome de domínio em um registrador. Também podem se referir ao nome da marca ou do projeto, identificando-os para clientes em potencial. São precisamente esses domínios de segundo nível que podem conter um significado ou significar um relacionamento com um registrante. E é esse significado que pode lhes dar um valor no mercado de nomes de domínio, além de sua utilidade funcional (OCDE, 2004, p. 6). Os domínios de segundo nível, portanto, são o foco deste artigo, e doravante serão referidos apenas como "nomes de domínio".

Por fim, e para distinguir um país de outro, especialmente um que deseje usar um domínio de nível superior, como .gov ou .mil, dois domínios de letras foram estabelecidos e associados a países ou localizações geográficas, que são o domínio de topo de código de país (country code top-level domain - ccTLD) ou domínios de topo de código de país internacionalizados (internationalized top-level domains - IDN ccTLD), um nome de nível superior com um formato codificado que permite que conjuntos de caracteres não latinos ou outros caracteres especiais sejam usados (CRABB, 2018). O ccTLD para o Brasil (“.br”) é gerido pelo Núcleo de Informação e Coordenação do Ponto BR (NIC.br), associação que também é responsável pelo registro de nomes de domínio e pela alocação de endereços IP.

A alocação de nomes de domínio pode ser feita de forma originária, a quem primeiro o solicitar (princípio do first come, first served), ou de forma derivada, por meio da transferência (geralmente a título oneroso) entre titulares. Assim, caso alguém pretenda registrar um nome de domínio já registrado em nome de terceiro, é possível adquirir o direito de registrá-lo do atual titular, ou seja, da pessoa ou empresa que o registrou mais recentemente e que possui os direitos de uso do domínio. O potencial financeiro dessas transações é tal que alguns registradores e outras empresas oferecem serviços relacionados à revenda de nomes de domínio, o que pode envolver um (demorado e complexo) processo de licitação ou leilão (ICANN, 2010, p. 3). Outros, de má-fé, realizam o registro originário com o intuito exclusivo de posterior revenda do domínio, prática que se convencionou chamar de cyber-grilagem (em inglês, cybersquatting).

A prática conhecida como cybersquatting é um dos problemas que mais atingem os detentores de marcas e de domínios no meio digital (KING, 2000). A expressão refere-se a um registro de domínio feito de má-fé e está relacionada à apropriação indevida de marcas. O cybersquatting consiste no ato de solicitar um registro de nomes conhecidos com o intuito de fazer com que os detentores das marcas paguem para obter o domínio: há agentes que se apressam para registrar nomes iguais ou semelhantes a marcas conhecidas no mercado antes que os detentores das marcas tenham a oportunidade de fazê-lo, com o intuito de revender os domínios aos respectivos detentores das marcas (KING, 2000; GILWIT, 2003; CURTIN, 2010).

Um subtipo de cybersquatting que tem se tornado frequente é o chamado typosquatting, que consiste no registro de nomes de domínio com erros de digitação ou ortografia como variações de páginas populares ou marcas. Assim, não se adota o nome exato da marca, mas 
registram-se nomes de domínios populares sujeitos a erros de tipografia por parte dos usuários no processo de tentar acessá-los. O intuito, nesse tipo específico de cybersquatting, não é tanto revender o domínio aos detentores da marca, mas cooptar o tráfego à página original para o domínio registrado de modo a gerar lucro com publicidade (GILWIT, 2003).

No Direito brasileiro, o typosquatting e o cybersquatting são tipificados como crimes de concorrência desleal pela Lei n. 9.279/1996 (BRASIL, 1996), mais conhecida como Lei de Propriedade Industrial (LPI), e relacionam-se ao uso indevido de marca com intuito de causar confusão ao consumidor. Exploraremos o tema em detalhes na próxima seção.

\section{I.2. ANÁliSE ECONÔMICA DOS DIREITOS DE PROPRIEDADE INTELECTUAL}

O campo conhecido como Análise Econômica do Direito (AED) refere-se ao estudo dos impactos das regras no comportamento dos indivíduos. A análise é dita "econômica”, tendo em vista que utiliza os instrumentos analíticos típicos da Microeconomia, i.e., a presunção de racionalidade e a análise da eficiência (HOLMAN, 2004). Em outras palavras, a AED "utiliza a teoria econômica para analisar o mundo jurídico" (CALABRESI apud HYLTON, 2019, p. 77). Trata-se de uma abordagem pertinente para o objeto estudado, tendo em vista sua relevância na justificativa dos direitos de propriedade, incluindo aqueles que versam sobre os bens imateriais, e sua utilidade na análise da eficiência, propósito deste artigo.

Primeiro, cabe tecer algumas considerações sobre como o arcabouço instrumental da Economia é utilizado na justificativa dos sistemas de proteção de propriedade intelectual. Em linhas gerais, a teoria econômica classifica os bens segundo duas características: exclusão e rivalidade (MANKIW, 2020, p. 174). Um bem é excludente quando as pessoas podem ser impedidas de usá-lo e é rival quando o fato de uma pessoa utilizá-lo diminui a disponibilidade do bem para as demais. Da conjugação dessas duas características, resultam quatro tipos de bens, esquematizados no Quadro 1, a seguir.

QUadro 1 - ClassificAÇÃo ECONÔMICA DOS BENS

RIVAL NÃORIVAL

\begin{tabular}{lll}
\hline EXCLUDENTE & BENS PRIVADOS & BENS ARTIFICIALMENTE ESCASSOS \\
& MAÇÃS & PROTEÇÃO CONTRA INCÊNDIOS \\
& ROUPAS & TV A CABO \\
\hline NÃO EXCLUDENTE & RECURSOS COMUNS & BENS PÚBLICOS \\
& PEIXES NO MAR & FOGOS DE ARTIFÍCIO \\
& AREÁGUA PUROS & CRIAÇÕES TÉCNICAS E ESTÉTICAS
\end{tabular}

Fonte: Adaptado de Mankiw (2020, p. 174). 
De acordo com tal classificação, os bens públicos são aqueles que não são nem rivais nem excludentes, o que facilita sua apropriação e reprodução simultânea. Bens intelectuais, como as criações técnicas e estéticas, têm características semelhantes às dos bens públicos, tendo em vista sua natureza imaterial (BOYLE, 2008). Segundo a perspectiva da AED, como não se pode impedir o acesso a esses bens, há incentivos para que pessoas denominadas "caronas" (free riders) usem tais bens sem pagar por eles (LANDES e POSNER, 1989; MANKIW, 2020). O resultado, por sua vez, é um desincentivo a que tais criações sejam disponibilizadas em quantidades socialmente desejáveis, uma vez que seus criadores não dispõem de meios para assegurar o retorno do investimento (de tempo, esforço e dinheiro) feito em sua criação (LANDES e POSNER, 1989). Para corrigi-lo, criam-se os direitos de propriedade intelectual.

Em uma perspectiva utilitarista, ${ }^{2}$ os direitos de propriedade intelectual são entendidos como incentivos para a produção de bens imateriais, considerando a relação entre custos e recompensas. Nesse sentido, é conferido a seus titulares um conjunto de direitos exclusivos e temporários que lhes permitem autorizar ou impedir atos como o uso, a reprodução e a distribuição da criação intelectual em questão. Como consequência desse monopólio jurídico, o bem protegido torna-se excludente, já que o titular do direito de propriedade intelectual poderá cobrar pelo seu uso, possibilitando-lhe recuperar os investimentos em sua criação e, com isso, continuará contribuindo com o patrimônio científico e artístico (BARBOSA, 2003; BOYLE, 2008). Trata-se, portanto, de um artifício que visa equiparar os bens de natureza imaterial aos produtos físicos.

A AED pressupõe que o decréscimo do preço de mercado de determinado bem desencoraja sua produção, o que justificaria a adoção de sistemas de proteção (FISHER, 2001; LANDES e POSNER, 2003). Um corolário disso é que os direitos de propriedade intelectual introduzem uma escassez artificial aos bens intelectuais, a qual serve como incentivo para a produção pelos agentes, tendo em vista a relação potencialmente positiva de recompensa em relação ao esforço (MENELL, 2000; FISHER, 2001).

A proteção à propriedade intelectual abrange três ramos vastos e heterogêneos: propriedade industrial, direitos autorais e conexos e direitos sui generis. O Quadro 2, a seguir,

2 Segundo William Fisher (2001), existem quatro teorias que justificam a criação de direitos de propriedade intelectual. A teoria utilitarista busca a maximização do bem-estar social, o que, no caso da propriedade intelectual, significa restringir o acesso a bens intelectuais como forma de estimular o investimento em sua criação. A teoria do trabalho defende a instituição de direitos de propriedade intelectual como forma de garantir o direito natural do criador aos frutos de seu trabalho intelectual. A teoria da personalidade defende a PI como forma de proteger criações por meio das quais a personalidade humana se expressa. Por fim, a teoria do planejamento social defende que direitos de propriedade intelectual devem ser desenhados de forma a promover o atingimento de uma cultura justa e atrativa. Neste artigo, focamos a teoria utilitarista por ser largamente utilizada e por suas interfaces com a AED. 
NOMES DE DOMÍNIO E PROPRIEDADE INTELECTUAL: REFLEXÕES SOBRE RESOLUÇÃO DE CONTROVÉRSIAS : 8

detalha os direitos disponíveis sob cada um deles, os quais se diferenciam essencialmente em função da natureza da criação que é objeto de proteção.

QUADRO 2 - RAMOS DO DIREITO DE PROPRIEDADE INTELECTUAL

PROPRIEDADE INDUSTRIAL

\begin{tabular}{lll}
\hline PATENTES & DIREITOS AUTORAIS & TOPOGRAFIA DE CIRCUITO INTEGRADO \\
\hline DESENHO INDUSTRIAL & DIREITOS CONEXOS & CULTIVARES \\
\hline
\end{tabular}

MARCAS

INDICAÇÕES GEOGRÁFICAS

REPRESSÃO À CONCORRÊNCIA DESLEAL
CONHECIMENTO TRADICIONAL

Fonte: Adaptado de Jungmann (2010, p. 24).

No Brasil, a propriedade industrial é protegida por meio da LPI e administrada pelo Instituto Nacional da Propriedade Industrial (INPI). Apesar do termo "industrial”, o art. 1(3) da Convenção da União de Paris para a Proteção da Propriedade Industrial (BRASIL, 1975) estabelece que tais direitos devem ser entendidos de forma ampla, aplicando-se "[...] não só à indústria e ao comércio propriamente ditos, mas também às indústrias agrícolas e extrativas e a todos os produtos manufaturados ou naturais, por exemplo: vinhos, cereais, tabaco em folha, frutas, animais, minérios, águas minerais, cervejas, flores, farinhas" (BRASIL, 1975).

$\mathrm{O}$ direito de patente protege tanto invenções quanto modelos de utilidade, pelos prazos de 20 e 15 anos, respectivamente. Esse sistema foi “[...] concebido para promover a inovação e a transferência e disseminação de tecnologia, em benefício mútuo de inventores, usuários das invenções e o público em geral” (OMPI, 2016, p. 8, tradução livre), uma vez que o direito é concedido em troca da divulgação do conteúdo patenteado, o qual passa a estar disponível para toda a sociedade.

Já o desenho industrial diz respeito a criações (composições de linhas e cores ou formas tridimensionais) de caráter meramente ornamental, sem qualquer vinculação à função técnica do objeto em que é aplicado (SILVEIRA, 2014, p. 7). O prazo de proteção no Brasil é de dez anos, prorrogáveis por três períodos sucessivos de cinco anos (BRASIL, 1996).

A marca, por sua vez, consiste em "[...] um sinal que se acresce ao produto para identificá-lo e deve ser suficientemente característica para preencher tal finalidade” (SILVEIRA, 2014, p. 14). No Brasil, o registro de marca é concedido pelo INPI pelo prazo de dez anos, prorrogáveis sucessivamente pelo mesmo período, e, como regra, compreende a exclusividade apenas no ramo de atividade descrito no pedido de registro (BRASIL, 1996). Esse direito de 
propriedade industrial comumente representa um dos ativos mais valiosos de uma empresa na medida em que veicula informações essenciais ao processo de compra, como qualidade, prestígio e reputação. Vincula-se à questão dos domínios, pois, em muitos casos, os endereços representam e expressam uma marca específica. Segundo Diana de Mello Jungmann (2010, p. 36-38), as marcas podem ser classificadas segundo dois critérios. Quanto a seu conteúdo estético, elas podem ser nominativas (combinação de letras e/ou números), figurativas (apenas imagens), mistas (combinação de marca nominativa e figurativa) ou tridimensionais (a própria forma do produto ou sua embalagem). Quanto ao tipo, dividem-se em marcas de produto ou serviço, de certificação (atesta conformidade de um produto/serviço a uma norma ou especificação técnica) ou coletiva (identifica produtos/serviços provenientes de uma dada entidade associativa).

Também um signo distintivo, a indicação geográfica refere-se a bens ou serviços que adquiriram reputação (no caso da indicação de procedência) ou características (no caso da denominação de origem) derivadas essencialmente do território do qual se originam (BRASIL, 1996). Alguns exemplos incluem a indicação de procedência "Santos" para sapatos e a denominação de origem "Vale dos Vinhedos" para vinhos produzidos naquela região da Serra Gaúcha. O uso das indicações geográficas é assegurado por tempo indeterminado àqueles produtores estabelecidos naquela localidade específica (BRASIL, 1996).

Por fim, a LPI também protege os empresários contra 14 atos específicos de concorrência desleal, listados em seu art. 195. No que tange ao cybersquatting, destacam-se aqueles previstos nos incisos III (emprego de meio fraudulento para desviar clientela de outrem, em proveito próprio ou alheio), IV (uso ou imitação de expressão ou sinal de propaganda alheios, de modo a criar confusão entre os produtos ou estabelecimentos) e V (uso indevido de nome comercial, título de estabelecimento ou insígnia alheios). Essa é uma proteção suplementar àquela ofertada pelos institutos anteriores, e é "[...] particularmente importante para a proteção de conhecimento, tecnologia ou informação não suscetíveis de proteção por patente, mas que podem ser necessários para uma melhor utilização de uma invenção patenteada" (OMPI, 2016, p. 22, tradução livre).

Em contraste, os direitos autorais consistem na dimensão da propriedade intelectual associada aos trabalhos criativos e originais. Segundo a Lei de Direitos Autorais (LDA) brasileira Lei n. 9.610, de 19 de fevereiro de 1998 (BRASIL, 1998) -, a expressão "direitos autorais" é utilizada para se referir a direitos de autor e conexos (art. $1^{\circ}$ ). Consistem em direitos exclusivos na medida em que promovem um monopólio sobre o uso das obras, como textos, interpretações e fonogramas (VASCONCELOS, 2010; BRUGUIÈRE, 2011).

Tal como nos demais direitos de propriedade intelectual, a prerrogativa de autorizar o uso dos bens intelectuais protegidos por direitos autorais compete aos seus respectivos titulares, ainda que possa ser transferida a terceiros (BRANCO e PARANAGUÁ, 2009; VASCONCELOS, 2010). Diferentemente do que ocorre na propriedade industrial, porém, o art. $8^{\circ}$ da LDA nega proteção a "nomes ou títulos isolados". Como regra geral, isso significa 
que é possível proteger o conteúdo de sítios eletrônicos pelos direitos autorais, mas tal proteção não se aplica aos nomes de domínio isoladamente. ${ }^{3}$

Pelo exposto, observa-se que a teoria utilitarista, com base na AED, explica os monopólios concedidos no âmbito da propriedade industrial e dos direitos autorais mediante o cálculo custo-benefício realizado pelos agentes. Essa teoria, por sua vez, parte do pressuposto microeconômico de que indivíduos são racionais e, portanto, buscam maximizar seus benefícios. Nesse sentido, o monopólio de exploração consiste no incentivo para a produção de bens imateriais face aos desafios impostos pela natureza não rival e não excludente de tais bens (LANDES e POSNER, 2003).

Essas mesmas justificativas podem ser aplicadas ao registro de domínio. A necessidade de proteção aos nomes de domínio reside em justificativas que versam sobre a justa concorrência e o desenvolvimento econômico, ao passo que garantem a lisura do processo concorrencial e geram incentivos para os detentores das marcas, além de proteger os consumidores. Por outro lado, também possui uma dimensão moral na medida em que o uso de determinado nome afeta a reputação do(a) dono(a) do domínio. No entanto, enquanto a propriedade intelectual versa sobre o conteúdo, os nomes de domínio consistem no título relacionado, um sinal que se presta ao mesmo objetivo distintivo que as marcas nominativas.

Apesar dessa distinção teórica, na prática, a relação entre nome de domínio e propriedade intelectual é bastante mesclada, e uma das questões tratadas reiteradamente na resolução de litígios. Para alguns, a prática de cybersquatting pode ser potencialmente uma violação de marca, por caracterizar-se como um uso por terceiro não autorizado pelo titular, e também um ato de concorrência desleal, tendo em vista que promove confusão e frustração aos consumidores (CURTIN, 2010). Há, porém, quem argumente que o nome do domínio não guarda relação com a propriedade relacionada, porquanto é tão somente um nome. Por outro lado, detentores de marca afirmam que o nome do domínio é um dos indicadores do produto e, dessa forma, integra os direitos sobre a marca (KING, 2000).

Portanto, identifica-se que há uma função social aplicada aos nomes de domínio, uma vez que há o atendimento do direito coletivo de acesso à informação, o que se traduz no correto direcionamento do usuário ao conteúdo que ele procura. A obrigatoriedade de o nome de domínio atender a uma função social trespassaria, portanto, o direito de propriedade, já que o nome de domínio registrado seria afetado pelo exercício de sua função social. Dessa forma,

3 Ressalta-se que o campo dos direitos autorais, ainda que não esteja diretamente afetado às questões relativas a domínio, enfrenta desafios semelhantes aos que atingem outros direitos intelectuais no que tange à relação entre tecnologia e propriedade imaterial - citam-se aqui a territorialidade dos direitos (diante da pretensão universal da internet) e a característica descentralizada do sistema internacional, que levanta questões relacionadas à soberania e ao papel dos Estados-Nações (HELFER, 2001). 
o direito de propriedade do nome de domínio sofreria o escrutínio do art. $5^{\circ}$, XXIX, da Constituição Federal de 1988, que garante a proteção à propriedade das marcas tendo em vista o interesse social, e do art. $2^{\circ}$ da LPI, que assegura a proteção dos direitos relativos à propriedade industrial, considerado o seu interesse social.

Desse modo, a função social do nome de domínio implica a vedação ao proprietário do domínio não titular da marca aludida do exercício de determinadas faculdades, passando a ser obrigado a exercer determinados direitos elementares da propriedade intelectual. Assim, a função social dos nomes de domínio (i) fomentaria o desenvolvimento do patrimônio intelectual dos devidos titulares de determinada marca; e (ii) promoveria a segurança jurídica para a criação de novas marcas, assegurando-lhes a disponibilidade de promoção na internet via nomes de domínio.

Independentemente da posição adotada, fato é que o cybersquatting é um problema relevante para os detentores de marca, como demonstra o número de casos nos diferentes sistemas de resolução de controvérsias disponíveis. E, considerando-se a relevância que o comércio eletrônico assumiu, prevenir e coibir sua prática tornou-se cada vez mais importante. Por tal razão, importantes organizações sem fins lucrativos dispõem de sistemas de resolução de conflitos sobre nomes de domínio, sendo o principal deles a Corporação da Internet para Atribuição de Nomes e Números (ICANN, na sua sigla em inglês), cujos mecanismos serão detalhados a seguir.

No âmbito da AED, a eficiência de tais mecanismos de resolução de controvérsias remete à diminuição dos conflitos e à solução dos embates. Partindo da ideia de racionalidade - a qual se relaciona ao estereótipo do indivíduo autointeressado -, a eficiência significa que os regulados apresentarão o comportamento almejado pela regulação devido à existência de certos incentivos ou punições. Dessa forma, o objetivo é identificar de que forma as regras são transformadas em incentivos para maximizar a agregação de preferências dos membros da sociedade (DAGAN e KREITNER, 2021) - disso resulta o viés utilitarista da análise. Ademais, a resolução de controvérsias implica custos e ganhos que devem ser considerados pelos agentes (KAPLOW e SHAVELL, 2002).

Dessa forma, a questão central da AED refere-se a que tipo de comportamento é induzido pelas regras do jogo e se o resultado promove a maximização das preferências ou os objetivos sociais almejados pela legislação. Keith Hylton (2019) divide ainda a análise econômica em dois tipos: positiva, a qual se refere à compreensão dos fenômenos ou de convenções, e a normativa, cujo objetivo é desenhar instituições ótimas ou reformar as instituições existentes. O presente artigo se debruça sobre os dois vieses: ao discorrer sobre o fenômeno do cybersquatting, tentamos verificar suas relações com a propriedade intelectual; ao analisar os mecanismos de resolução de controvérsias, buscamos explorar a eficiência de tais instrumentos de modo a trazer lições para o contexto brasileiro.

Se, por um lado, a AED pode fornecer instrumentos analíticos para a compreensão dos processos decisórios e dos comportamentos dos agentes, por outro lado, cabe o questionamento 
da relação entre a ideia de racionalidade e outros objetivos morais normativos além da eficiência, tais como a autonomia e a justiça distributiva (DAGAN e KREITNER, 2021).

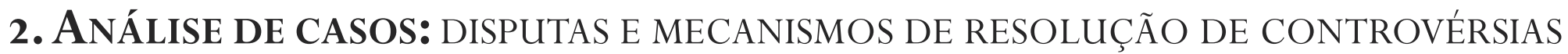

\section{I. A InSTITUCIONALIZAÇÃo DOS MECANiSMOS DE CONTROVÉRSiAS}

Até o início dos anos 1990, a ausência de um mecanismo institucionalizado para a resolução de conflitos sobre nomes de domínio fazia com que os registrantes fossem responsáveis por garantir que o nome registrado não infringisse marcas registradas (GEIST, 2002a). O primeiro sistema formal viria a ser criado pela empresa Network Solutions Inc., em julho de 1995, e permitia que titulares de marcas registradas contestassem nomes de domínio que violassem esses direitos (GEIST, 2002a).

Hoje, os procedimentos de resolução de disputas sobre domínios têm sua base na Uniform Domain-Name Dispute-Resolution Policy (UDRP) (ICANN, 1999), ou "Política para Resolução Uniforme de Litígios sobre Nome de Domínio”, que é o processo-padrão utilizado para contendas de gTLDs. Essa Política foi aprovada pela ICANN em 1999 e conta hoje com diversos documentos suplementares, como as Regras que regem seus procedimentos. Atualmente, a resolução de conflitos sobre nomes de domínio sob a UDRP rege-se pelas Regras aprovadas em 2013 (ICANN, 2013), compostas de 21 itens, entre definições e procedimentos. Segundo seu item 3, para iniciar uma apuração é necessário que o registrante reclamante comprove cumulativamente:

(1) de que forma os nomes de domínio são idênticos ou causam confusão com uma marca registrada ou comercial sobre a qual o Reclamante tem direito; e

(2) o motivo pelo qual deve ser considerado que o Reclamado (proprietário do nome de domínio) não tem direitos ou interesses legítimos em relação aos nomes de domínio a que se refere a denúncia; e

(3) o motivo pelo qual os nomes de domínio devem ser considerados registrados e utilizados de má-fé. (ICANN, 2013)

Cabe destacar que a terceira regra remete ao conceito de cybersquatting, tendo em vista que o dolo é uma de suas características fundamentais. Isso porque, tal como explicado anteriormente, a prática relaciona-se a fins específicos, i.e., de vender o nome de domínio ou de extrair benefícios da confusão no mercado. Ressalte-se que, dado que o registro de domínios ocorre por ordem de chegada e sem investigação prévia por parte do órgão de registro, é de se esperar que a maior parte dos casos em disputa ocorra por notória má-fé do primeiro registrante, que pratica cybersquatting na esperança de revender o domínio diretamente ao registrante reclamante, titular da marca (POPOVIĆ, 2011, p. 17). Dessa 
forma, na lógica da AED, a ausência de investigação induz ao comportamento de infração, tendo em vista que não há óbices formais ao registro de domínios associados a marcas preexistentes. Na falta de um mecanismo de resolução de disputas, a prática de cybersquatting seria ainda mais encorajada devido ao baixo custo da ação e a potencialidade de benefícios econômicos para os infratores.

Por meio da UDRP, a ICANN conseguiu desenvolver, em nível global, um procedimento de resolução de disputas transparente, on-line e juridicamente vinculante, ${ }^{4}$ permitindo aos proprietários de marcas registradas lutarem contra violações cibernéticas com eficiência. Essa é uma conquista positiva para o desenvolvimento do comércio eletrônico, pois favorece a confiança dos consumidores na internet, reduzindo o número de nomes de domínio registrados com intuito fraudulento. Esse sucesso, principalmente entre os titulares de marcas, foi alcançado com a criação de um procedimento econômico, com as características de: (i) participação obrigatória; e (ii) mecanismo autoaplicável.

Após décadas de existência, porém, algumas observações merecem ser feitas. A primeira delas é de que grande parte dos casos de UDRP são casos-padrão, ou seja, com pleitos e acusações de ilícitos e danos semelhantes, e com decisões principalmente a favor dos reclamantes (GEIST, 2002b). Essa alta taxa de reivindicações bem-sucedidas pode ser justificada pelo fato de o réu não participar dos painéis de resolução, de forma que os painelistas decidem sob a presunção de veracidade das alegações factuais do reclamante. Por outro lado, argumenta-se que o réu não participa dos painéis de resolução porque as chances de êxito são baixas (DIÉGUEZ, 2008, p. 10). Assim, tais aspectos contribuem para que o processo favoreça os reclamantes.

Em seu estudo sobre quão justos são os procedimentos sob a UDRP, Geist (2002a) identificou diferenças dramáticas no resultado de casos julgados por um ou por três especialistas; o autor também aponta que, embora feita de forma aleatória, a alocação dos casos gera resultados parciais na medida em que a maioria dos casos é alocada para especialistas pró-reclamantes. Nesse sentido, Diéguez (2008, p. 17) afirma que o viés pró-reclamante deriva do fato de que os interesses de todas as partes não estão igualmente representados dentro das entidades normatizadoras (ICANN e OMPI) e entre aqueles que efetivamente aplicam as normas (provedores de serviços e painelistas da UDRP). Não é incomum, portanto, que a idoneidade do processo de julgamento seja posta à prova.

4 A obrigatoriedade da UDRP decorre da inserção de cláusula em contratos de adesão para a compra e venda de domínios celebrados entre o registro (ICANN) e o registrador (ISP) ou entre o registrador e o registrante (detentor do nome de domínio). A cláusula em questão determina que certas disputas de marcas relacionadas a cybersquatting - entre o registrante e o proprietário da marca - serão resolvidas por um fornecedor de resolução de disputas autorizado pela ICANN. 
Assim, se, por um lado, de acordo com a AED, o viés pró-reclamante poderia ser visto como uma forma de gerar incentivos contra o comportamento infrator, já que o ônus recai sobre o réu, por outro, levanta questões sobre o dilema entre "eficiência” e "justiça”. Como a análise econômica não se vincula a uma perspectiva moral específica, em alguns casos, valores normativos como "autonomia", "democracia” e "justiça” ficam de fora do debate (DAGAN e KREITNER, 2021). Portanto, a diminuição no número de infrações ou de reclamações é um parâmetro da eficiência, mas não atesta a justiça do processo.

No que concerne aos ccTLDs, cada país tem seus órgãos próprios para registro e resolução de contendas. Tendo em vista os altos custos e a demora na conclusão dos litígios submetidos ao Poder Judiciário, bem como a negociação lenta e custosa da transferência de domínio entre os cybersquatters e os titulares das marcas, o Brasil, por meio de seu Comitê Gestor da Internet (CGI.br), optou por alocar ao NIC.br o registro dos domínios “.br” e a administração ${ }^{5}$ do Sistema Administrativo de Conflitos de Internet (SACI-Adm), responsável pela resolução de litígios entre o titular de um nome desse domínio e qualquer terceiro que conteste a legitimidade do registro.

Analisando o modelo estadunidense da UDRP, o CGI.br entendeu que adotá-lo não seria o caminho mais adequado - mesmo levando-se em consideração o prestígio já conquistado em diversos países por sua eficácia e celeridade na solução de conflitos que envolvem nomes de domínio (ANGELINI, 2012, p. 14). O órgão também desaprovou a ideia de solucionar tais conflitos por meio de arbitragem, uma vez que a formalidade estabelecida pela Lei Arbitral e o seu custo seriam proibitivos.

Além disso, os conflitos de domínio no Brasil exigiam fatores e especificidades distintos dos que eram implementados via UDRP, uma vez que os conflitos brasileiros priorizavam (i) a liberdade das partes em escolherem a entidade que administra esse procedimento, incluindo entidades nacionais; (ii) assegurar que o procedimento fosse realizado em idioma português; (iii) que fosse julgado apenas por especialistas brasileiros; (iv) que abrangesse também questões envolvendo nomes empresariais e nomes artísticos; e (v) seguisse as regras já adotadas para domínios registrados no ".br” (ANGELINI, 2012, p. 14).

Buscando dar maior efetividade aos mecanismos de solução de disputas relativas ao domínio “.br”, o CGI.br optou por um sistema extrajudicial próprio, que contemplasse as especificidades da realidade brasileira. Apesar disso, é interessante destacar que o Regulamento do SACI-Adm é similar ao da UDRP: o reclamante poderá requerer a abertura do procedimento a qualquer uma das instituições credenciadas, ${ }^{6}$ requerendo-lhe o cancelamento ou a

5 Ao NIC.br cabe apenas a implementação do sistema, de modo que ele não participa da administração dos procedimentos nem interfere no julgamento do conflito (ANGELINI, 2012, p. 15).

6 As instituições credenciadas são, atualmente, a Câmara de Comércio Brasil-Canadá (CCBC), a Organização Mundial da Propriedade Intelectual (OMPI) e o Centro de Solução de Disputas, Mediação e Arbitragem 
transferência do domínio - qualquer pretensão relativa à obtenção de indenizações deve ser solicitada por via judicial. Algumas vantagens notadas são: (i) decisões proferidas em um curto período de tempo; (ii) profissionais especializados credenciados no CGI.br; e (iii) baixos custos relacionados.

Outras opções a que o reclamante poderá recorrer são a arbitragem e o Poder Judiciário. A primeira é um compromisso entre as partes interessadas, que elegem um terceiro de sua confiança com competência e atribuições bem definidas para decidir o conflito sobre uma determinada matéria (CARMONA, 1990). Apesar de mais onerosa que o procedimento administrativo, poder-se-ia argumentar que a arbitragem seria preferível ao SACI-Adm na medida em que permite uma decisão executável para a disputa, além da livre escolha dos especialistas responsáveis por julgar o conflito e do centro responsável pela administração do procedimento.

Por fim, o Judiciário poderá ser acionado seja como via originária, para questionar a alocação do domínio, seja como via secundária, para recorrer da decisão administrativa ou arbitral. Essa, no entanto, tende a ser uma escolha difícil, dado que seus julgadores como regra não são especializados na temática digital e, no caso particular do Brasil, a resolução em definitivo dos casos costuma ser notoriamente morosa, o que por sua vez implica altos custos para a manutenção do processo.

\subsection{A EXPERIÊNCIA BRASILEIRA EM RESOLUÇÃO DE CONFLITOS SOBRE NOMES DE DOMÍNIO}

Explicados os mecanismos de resolução de conflitos envolvendo nomes de domínio, tanto no mundo quanto no caso particular do Brasil, cabe agora nos debruçarmos sobre o desenrolar dessas disputas envolvendo registros de nomes de domínio sob o código-país brasileiro (“.br”), nos âmbitos extrajudicial e judicial. Para o primeiro grupo, focaremos as decisões proferidas pelas instituições credenciadas ao SACI-Adm: CCBC, CSD-PI e OMPI. Para o segundo, trabalharemos exclusivamente com o STJ, por ser a instância máxima brasileira para questões infraconstitucionais. Dado o alto número de decisões no primeiro grupo, as análises serão de natureza quantitativa. Em complementação, foi realizada uma análise qualitativa dos casos no STJ com vistas a aprofundar os mecanismos que norteiam esse tipo de controvérsia.

No que toca às 297 decisões analisadas do SACI-Adm, que cobrem o período de abril de 2011 a outubro de 2019, vê-se uma boa produtividade das instituições credenciadas, cuja

em Propriedade Intelectual (CSD-PI) da Associação Brasileira da Propriedade Intelectual - os valores para iniciar o processo de arbitragem variam conforme a instituição escolhida. Apesar de possuírem seus próprios regulamentos relativos ao procedimento administrativo, todos utilizam como regras procedimentais (dispute policy) o texto matriz do SACI-Adm. 
média é de 33 decisões por ano, com um pico em 2017 (52 decisões, o que equivale a uma média de uma por semana) e um vale em 2011 (três decisões) (ver Gráfico 1). O tempo de tramitação dos casos também é digno de nota: segundo informação transmitida pelo SACI-Adm, uma decisão sobre disputas de nome de domínio é dada, em média, no prazo de 40 dias.

\section{GRÁFICO 1 - DiSTRIBUIÇÃO DE DECISÕES DO SACI-ADM POR ANO (20I I -20I9)}

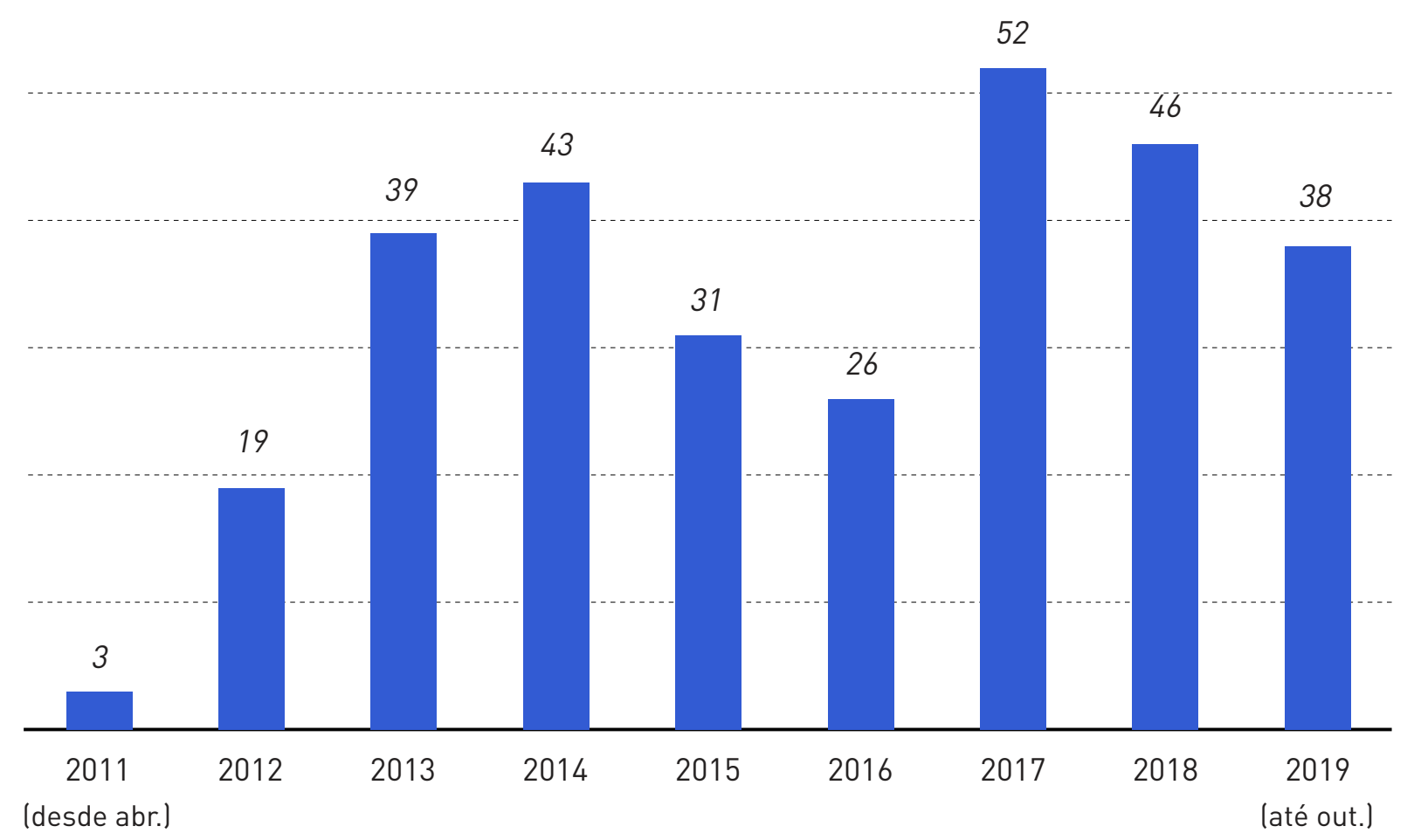

Fonte: Elaboração própria, com dados de https://registro.br/dominio/saci-adm/. Acesso em:

11 jun. 2020.

Outro ponto a se destacar diz respeito ao índice de vitória dos reclamantes: 264 casos $(88,9 \%)$ culminaram na transferência do domínio, confirmando o padrão visto na UDRP de favorecimento aos reclamantes. Quanto aos demais casos, houve 16 determinações de cancelamento de domínio $(5,4 \%)$ e outras 16 de manutenção, não tendo havido julgamento de mérito em apenas três casos (1\%) (ver Gráfico 2). ${ }^{7}$ Quanto à escolha da instituição credenciada, houve clara primazia do CSD-PI (194 decisões), seguida pela OMPI (95 decisões) e, em um distante terceiro lugar, a CCBC com oito decisões. Em consulta direta ao NIC.br sobre o assunto, foi informado que a preferência pelo CSD-PI reside em uma mera questão de custo, dado ser mais barato e rápido para a maioria dos casos.

7 A soma supera 297 casos, pois em dois deles houve simultaneamente a transferência e o cancelamento de domínios. 


\section{GRÁFICO 2 - DISTRIBUIÇÃO DAS DECISÕES POR RESULTADO E POR INSTITUIÇÃO CREDENCIADA ( 201 I - 20I9)}

\section{Decisões proferidas}

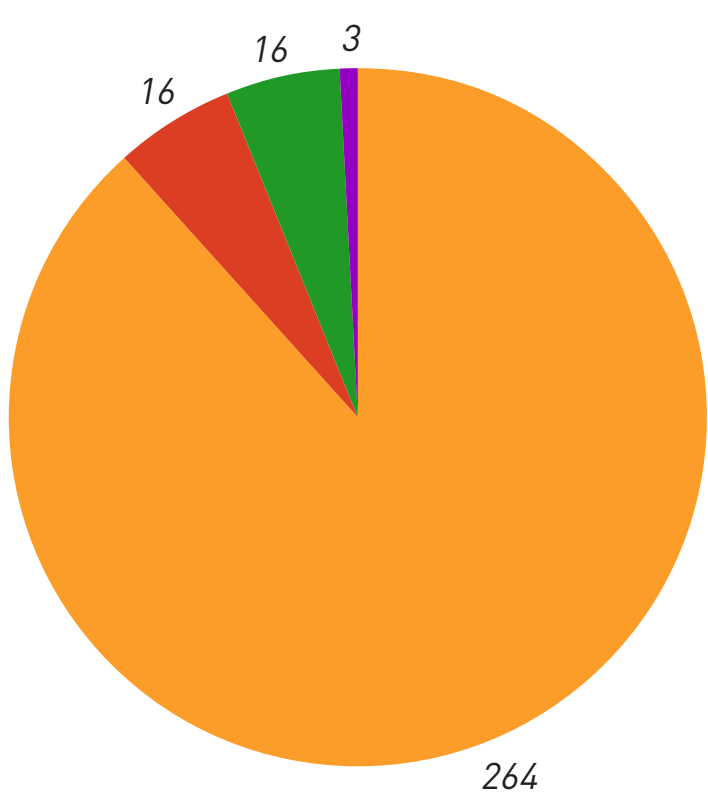

Distribuição por instituição credenciada

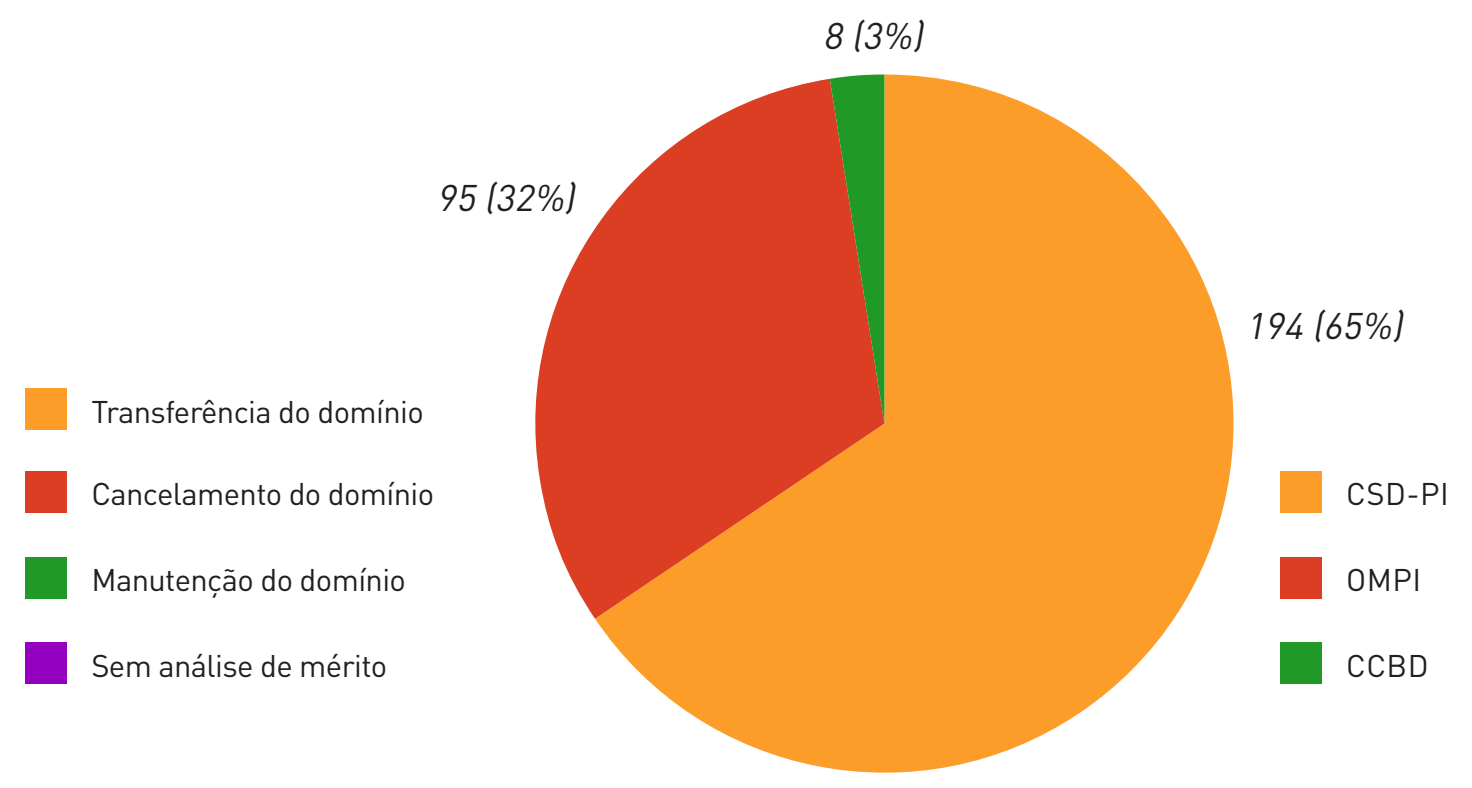

Fonte: Elaboração própria, com dados de https://registro.br/dominio/saci-adm/. Acesso em:

11 jun. 2020.

No STJ, por sua vez, a pesquisa por (“nome\$ de domínio”) retornou 14 acórdãos. Desses, foram excluídos oito que não discutiam questão de mérito ou cuja questão de mérito não dizia respeito a conflito sobre nomes de domínio, restando, portanto, seis casos.

Os acórdãos selecionados foram proferidos ao longo dos anos de 2013 a 2019, o que equivale a uma média de 0,85 casos julgados ao ano. Quanto ao tempo de tramitação, foi constatada uma média de 1.771 dias (4 anos, 10 meses e 6 dias) entre a data de autuação do processo no Tribunal e o seu julgamento pelos Ministros da Corte. O processo mais rápido tomou 90 dias, enquanto o mais demorado, 3.631 dias - praticamente dez anos.

No que se refere ao teor da decisão, o STJ apresenta uma tendência inversa à verificada na UDRP e no SACI-Adm: naquela Corte, dois terços dos acórdãos decidiram pela manutenção do domínio com o primeiro registrante, após análise das circunstâncias fáticas do caso. Comentaremos esse aspecto em detalhes mais adiante.

Em termos de custos, tem-se que os valores pagos ao STJ a título de custas são iguais para todos os participantes, dado que são preços tabelados. Quanto aos valores pagos aos advogados, estes forçosamente vão variar em razão dos profissionais escolhidos pelos litigantes, mas não estão publicamente disponíveis. Tendo em vista que o único acórdão que determina o pagamento de honorários advocatícios (BRASIL, 2019) o fixou em R \$10.000,00 (dez mil 
reais), é possível concluir que a via judicial sugere um patamar de gastos bem mais elevado que no sistema administrativo de resolução de disputas.

Para além da análise quantitativa, valem ainda algumas observações de ordem qualitativa. Um primeiro aspecto a se reparar refere-se ao baixo número de acórdãos proferidos. Cremos que isso deriva da combinação de dois fatores: (i) o fato de que o uso civil da internet é relativamente recente, tendo se iniciado a partir dos anos 1990; e (ii) o longo tempo que um processo leva para chegar ao STJ e ser decidido por ele - no caso dos acórdãos em discussão, a média apurada foi de 12 anos e 6 meses entre o ajuizamento da ação e a decisão do STJ.

O segundo aspecto diz respeito ao mérito das decisões, que identificamos ser bastante uniforme e girar em torno de quatro "teses", complementares entre si e resumidas a seguir:

1. A anterioridade do registro do nome empresarial ou da marca no órgão competente não assegura, por si só, ao seu titular o direito de exigir a abstenção de uso do nome de domínio na internet registrado por estabelecimento empresarial que também ostenta direitos acerca do mesmo signo distintivo (BRASIL, 2013a, 2013b).

2. No Brasil, o registro de nomes de domínio na internet é regido pelo princípio first come, first served, segundo o qual é concedido o domínio ao primeiro requerente que satisfizer as exigências para o registro, e que independe da análise mais aprofundada acerca da eventual colisão com marcas ou nomes comerciais registrados anteriormente em outros órgãos (BRASIL, 2013a, 2013b, 2015, 2017, 2018, 2019).

3. Apesar do princípio anteriormente citado, é possível que eventual prejudicado, titular de signo distintivo (nome empresarial ou marca) similar ou idêntico ao anteriormente registrado, conteste o nome de domínio conflitante. O domínio, no entanto, só poderá ser cancelado ou transferido se ficar comprovada a má-fé de seu titular no caso concreto, mediante atos antiéticos, oportunistas, direcionados a causar confusão nos consumidores, desvio de clientela, aproveitamento parasitário ou diluição da marca (concorrência desleal) (BRASIL, 2013a, 2013b, 2015, 2017, 2018, 2019).

4. A configuração de colidência indevida de signos distintivos ocorre com a mera possibilidade de confusão, não se exigindo prova de efetivo engano por parte de consumidores específicos. Constatada a violação, é devida a compensação por danos materiais e morais, independentemente de comprovação concreta de prejuízo material e do abalo moral resultantes do uso indevido, respectivamente (BRASIL, 2019). ${ }^{8}$

8 Apesar de só haver uma decisão, consideramos esta uma "tese" por haver farta jurisprudência do STJ sobre a desnecessidade de comprovação do efetivo engano dos consumidores para que a compensação seja devida, proferidas em um contexto mais amplo de direito das marcas. 
O fato de a jurisprudência sobre o tema ser uniforme é um fator positivo para as partes envolvidas, pois traz a segurança jurídica que é necessária à condução dos negócios. No entanto, a demora para se obter uma decisão final sobre um conflito de nome de domínio faz com que essa via não seja a primeira escolha das partes, havendo clara preferência pelo SACI- Adm, que se mostra rápido na solução das disputas submetidas a suas instituições credenciadas, dada a simplicidade e a celeridade de seu procedimento em comparação à alternativa judicial. Assim, no cálculo custo-benefício dos agentes, a dimensão temporal parece ser mais relevante na escolha do procedimento que a uniformidade jurisprudencial.

No que tange ao teor das decisões, a jurisprudência do STJ converge para uma análise da intenção dos agentes, destacando a necessidade de comprovação da má-fé do registrante originário nos pleitos envolvendo cancelamento de nomes de domínio, o que condiz com o conceito basilar de cybersquatting. Essa comprovação distingue fundamentalmente a prática de cybersquatting das violações à propriedade intelectual, que, na legislação brasileira, não dependem de dolo. ${ }^{9}$ Como afirma o próprio STJ, a violação da marca em si - independentemente da intenção de fazê-lo - já gera prejuízos ao seu detentor, de forma que sua caracterização decorre da "[...] mera comprovação da conduta ilícita [...]" (BRASIL, 2019).

Os argumentos, no entanto, oscilam entre perspectivas que diferenciam marcas de domínios e aquelas que enfatizam suas similaridades em razão da função de ambos na identificação dos serviços. É curioso também notar que a abordagem utilitarista - que justifica a proteção às marcas em razão do aumento do bem-estar da sociedade proporcionado pelo maior acesso a bens intelectuais - aparece de forma marginal nas decisões, apenas quando elas consideram os efeitos causados pelo cybersquatting no público consumidor, os quais podem ser considerados como externalidades negativas na terminologia econômica.

Em que pesem os prejuízos econômicos causados pela prática de cybersquatting, é a dimensão moral que se destaca nas decisões proferidas, dado que o dolo é elemento essencial à prática. Novamente: é a intenção - e não o resultado em si - que caracteriza o ilícito. Do ponto de vista do STJ, portanto, o cybersquatting está muito mais atrelado a uma questão de Justiça que a um problema econômico. A dimensão utilitarista encontra-se apenas marginalmente na preocupação com a indução do consumidor ao erro, tendo em vista os prejuízos causados ao mercado e à concorrência - o que afeta o bem-estar da sociedade de maneira geral.

Ao analisarmos a eficiência dos processos em si, podemos considerar como parâmetros o custo do procedimento, o tempo entre o peticionamento e a decisão, bem como a quantidade de casos judicializados. Em um cálculo de custo e benefício, vemos que esses fatores apontam

9 Em alguns sistemas, o dolo afeta apenas a dosimetria da pena. 
para uma maior eficiência do sistema do SACI-Adm, o que converge com a preferência observada dos agentes pelo SACI-Adm, em detrimento da via judicial.

Enquanto a resolução administrativa de disputas sobre nomes de domínio ocorre em menos de um mês e meio, uma contenda judicial frequentemente leva mais de uma década para ser resolvida definitivamente. Além disso, não é necessária a assistência de um advogado no procedimento do SACI-Adm, o que também contribui para reduzir seus custos. Dessa maneira, a quantidade de casos efetivamente judicializados - o que indicaria a insatisfação com a decisão administrativa - pode ser considerada bastante pequena, presumindo-se que os dados dos processos encontrados sobre o assunto no STJ sejam todos oriundos da insatisfação com a decisão administrativa.

Porém, Hestermeyer (2002, p. 32) adverte que o que ocorre no âmbito administrativo não deixa de ser uma questão de natureza contratual entre registrador e registrante, que não apenas é passível de revisão judicial, mas também é sujeita às modificações legais que podem vir a ocorrer ao longo do tempo. Por fim, vale ressaltar ainda que a eficiência no procedimento não implica justiça ou mesmo eficiência de resultados, mais complexa de se analisar devido à necessidade de trabalhar com contrafactuais. Nesse sentido, face à ausência de dados sobre o comportamento esperado dos agentes, a diminuição das reclamações nos mecanismos de disputa é utilizada como parâmetro imperfeito da mitigação de atos ilícitos, os quais são difíceis de julgar tendo em vista o caráter moral-normativo do cybersquatting.

\section{CONCLUSÃO}

Embora a avaliação do dano causado por um caso de cybersquatting dependa de diversos fatores, pelos dados disponibilizados pelo SACI-Adm, é seguro afirmar que a chance de se converter a posse de um domínio em sede administrativa pela autoridade de registro brasileira é bastante grande - confirmando a percepção de autores como Michael Geist, no sentido de que processos baseados na UDRP têm forte viés em favor do reclamante.

Ressalte-se que, em uma eventual contenda judicial e/ou administrativa, não há garantia de que o proprietário de determinada marca ou nome terá o registro de domínio revertido em seu interesse. É necessário que seja comprovada alguma prática de concorrência desleal, que deverá estar permeada por má-fé daquele que primeiro registrou o nome de domínio.

A decisão de litigar ou não por nome de domínio é ponderada à luz de fatores como o custo de oportunidade ou o tempo, que podem ser cruciais para ações de divulgação de eventos e disponibilização de serviços. Uma oportunidade perdida, a vandalização de um website ou campanhas publicitárias malsucedidas podem causar danos irreparáveis a uma marca. Pode haver situações em que é economicamente mais viável apenas trocar o nome ou comprar o domínio do squatter, sem grandes transtornos.

Nesse sentido, a AED pode contribuir para entender as escolhas dos agentes em relação ao mecanismo de resolução de controvérsias escolhido. A pesquisa realizada demonstra que 
a velocidade da resolução das disputas é um fator fundamental na opção das empresas por determinado fórum, junto com o custo do procedimento e a probabilidade de se revisitar suas decisões no Judiciário. Nesse sentido, o mecanismo do SACI-Adm mostrou-se mais efetivo nos três aspectos. O risco de judicialização contra uma decisão administrativa existe, mas é um direito fundamental na estrutura jurídica brasileira. No entanto, os estudos e os dados concentram-se na eficiência do procedimento em si, tendo em vista a complexidade de se analisarem os resultados e a aplicação da justiça. Dessa forma, é necessário ainda aprofundar a análise dos impactos resultantes da instauração de diferentes mecanismos de resolução de controvérsias no que tange à diminuição dos litígios e das infrações. Isso requer a construção de indicadores mais sólidos de "eficiência” e "justiça”.

No que tange ao teor das decisões, a perspectiva utilitarista se manifesta apenas marginalmente na consideração dos efeitos da prática de cybersquatting no público consumidor. Os argumentos utilizados nas decisões judiciais de tal perspectiva enfatizam a dimensão moral da prática, pois abarcam a dimensão da má-fé ou da culpa. Nesse contexto, aproximam-se mais de discussões sobre o conceito de Justiça (definição de práticas justas e injustas) que de visões utilitárias de propriedade.

Por fim, cabe destacar que a relação entre domínios e propriedade intelectual é controversa. Ao passo que os nomes de domínio e as marcas consistem em institutos distintos, os dois sistemas guardam semelhanças, tais como a função de identificação de determinado produto ou serviço - como ressaltado pela Corte. Além disso, ambos se relacionam com a defesa da justa concorrência. De qualquer forma, é necessário ter claro que nomes de domínio não são meros identificadores visuais, referências para registro, ou associações a determinados serviços. São identidades que relacionam um nome a seu público e constroem vínculos de confiança, cuja proteção significa não apenas a proteção da propriedade, mas a manutenção dos princípios da transparência para com as expectativas do público e da boa-fé objetiva.

\section{REFERÊNCIAS}

ANGELINI, Kelli. SACI - o Sistema Administrativo de Conflitos de Internet implementado para domínios no “.br”. Revista PoliTICs, Rio de Janeiro, n. 13, p. 13-19, set. 2012. Disponível em: https: / / politics.org. br/sites/default/files/downloads/poliTICS_n13.pdf. Acesso em: 28 mar. 2020.

BARBOSA, Denis Borges. Uma introdução à propriedade intelectual. 2. ed. Rio de Janeiro: Lumen Juris, 2003.

BRANCO, Sérgio; PARANAGUÁ, Pedro. Direitos autorais. Rio de Janeiro: Editora FGV, 2009. 
BRASIL. Decreto n. 75.572, de 8 de abril de 1975. Promulga a Convenção de Paris para a proteção da Propriedade Industrial. Diário Oficial [da] República Federativa do Brasil. Brasília, DF, 10 abr. 1975. Disponível em: https://www2.camara.leg.br/legin/fed/decret/1970-1979/decreto-75572-8-abril-1975-424105publicacaooriginal-1-pe.html. Acesso em: 16 nov. 2019.

BRASIL. Lei n. 9.279, de 14 de maio de 1996. Regula direitos e obrigações relativos à propriedade industrial. Diário Oficial [da] República Federativa do Brasil. Brasília, DF, 15 maio 1996. Disponível em: http://www.planalto.gov.br/ccivil_03/leis/19279.htm. Acesso em: 16 nov. 2019.

BRASIL. Lei n. 9.610, de 19 de fevereiro de 1998. Altera, atualiza e consolida a legislação sobre direitos autorais e dá outras providências. Diário Oficial [da] República Federativa do Brasil. Brasília, DF, 20 fev. 1998. Disponível em: http://www.planalto.gov.br/ccivil_03/leis/19610.htm. Acesso em: 16 nov. 2019.

BRASIL. Superior Tribunal de Justiça. Recurso Especial n. 594.404/DF. Recorrente: Condomínio Conjunto Nacional. Recorrido: Ancar Gestão de Empreendimentos Ltda. Órgão Julgador: Terceira Turma. Relator: Min. RicardoVillas Bôas Cueva. Brasília, 5 set. 2013. Diário da Justiça Eletrônico, 11 set. 2013 a.

BRASIL. Superior Tribunal de Justiça. Recurso Especial n. 658.789/RS. Recorrente: Federação da Agricultura do Estado do Rio Grande do Sul - FARSUL. Recorrente: Fiat Line Importação Exportação Comércio e Representações Ltda. Órgão Julgador: Terceira Turma. Relator: Min. Ricardo Villas Bôas Cueva. Brasília, 5 set. 2013. Diário da Justiça Eletrônico, 12 set. 2013b.

BRASIL. Superior Tribunal de Justiça. Recurso Especial n. 1.238.041/SC. Recorrente: Geração Comércio de Automóveis Ltda. - Microempresa. Recorrido: Boeira e Boff Ltda. - Microempresa. Órgão Julgador: Terceira Turma. Relator: Min. Marco Aurélio Bellizze. Brasília, 7 abr. 2015. Diário da Justiça Eletrônico, 17 abr. 2015.

BRASIL. Superior Tribunal de Justiça. Recurso Especial n. 1.466.212/SP. Recorrente: DM Indústria Farmacêutica Ltda. Recorrido: Núcleo de Informação e Coordenação do Ponto BR - NIC.br. Órgão Julgador: Quarta Turma. Relator: Min. Luis Felipe Salomão. Brasília, 6 dez. 2016. Diário da Justiça Eletrônico, 3 mar. 2017.

BRASIL. Superior Tribunal de Justiça. Recurso Especial n. 1.571.241/MT. Recorrente: Marcos Antônio Moreira. Recorrido: Amaggi Exportação e Importação Ltda. Órgão Julgador: Terceira Turma. Relatora: Min. Nancy Andrighi. Brasília, 5 jun. 2018. Diário da Justiça Eletrônico, 8 jun. 2018.

BRASIL. Superior Tribunal de Justiça. Recurso Especial n. 1.804.035/DF. Recorrente: Decolando Turismo e Representações Ltda. Recorrido: Decolar.com Ltda. Órgão Julgador: Terceira Turma. Relatora: Min. Nancy Andrighi. Brasília, 25 jun. 2019. Diário da Justiça Eletrônico, 28 jun. 2019. 
BRUGUIÈRE, Jean-Michel. Droit des propriétés intellectuelles. 2. ed. Paris: Ellipses Édition, 2011.

BOYLE, James. The Public Domain: Enclosing the Commons of the Mind. New Haven: Yale University Press, 2008.

CARMONA, Carlos Alberto. Arbitragem e jurisdição. Revista de Processo, v. 58, p. 33-40, abr. /jun. 1990. Disponível em: https: / / bit.ly/3yhZ8M1. Acesso em: 31 jul. 2021.

CRABB, Kristin. Types of Domain Names: A Helpful Guide. Domain.com Blog, [s. 1.], 30 out. 2018. Disponível em: https://www.domain.com/blog/2018/10/30/domain-name-types/. Acesso em: 14 nov. 2019.

CURTIN, Thomas J. The Name Game: Cybersquatting and Trademark Infringement on Social Media Websites. Journal of Law and Policy, [s. 1.], v. 19, n. 1, p. 353-394, 2010. Disponível em: https:// brooklynworks.brooklaw.edu/cgi/viewcontent.cgi?article=1107\&context=jlp. Acesso em: 12 jun. 2020.

DAGAN, Hanoch; KREITNER, Roy. Economic Analysis in Law. Yale Journal on Regulation, 2021 . Disponível em: https: / /ssrn.com/abstract=3680686. Acesso em: 2 ago. 2021.

DIÉGUEZ, Juan Pablo Cortés. An Analysis of the UDRP Experience - Is ItTime for Reform? Computer Law \& Security Review: The International Journal of Technology Law and Practice, [s. 1.], v. 4, n. 24, p. 349-359, 2008.

ESTADOS UNIDOS DA AMÉRICA (EUA). U.S. Code. Title 15 - Commerce and Trade. Legal Information Institute, Cornell University, 3 jun. 2020. Disponível em: https://www.law.cornell.edu/uscode/text. Acesso em: 16 nov. 2019.

FISHER, William. Theories of Intellectual Property. In: MUNZER, Stephen R. (ed.). New Essays in the Legal and Political Theory of Property. Cambridge: Cambridge University Press, 2001 . p. 168-199. Disponível em: http:/ / elplandehiram.org/documentos/cursos/ftpi/FisherIPTheories.pdf. Acesso em: 12 jun. 2020.

FISHER, William. Promises to Keep: Technology, Law, and the Future of Entertainment. Stanford: Stanford University Press, 2004.

GEIST, Michael. Fair.com? An Examination of the Allegations of Systemic Unfairness in the ICANN UDRP. Brooklyn Journal or International Law, Brooklyn, v. 27, n. 3, p. 903-938, 2002a. Disponível em: http:/ / bitly.ws/oj6C. Acesso em: 19 jan. 2020.

GEIST, Michael. Funtamentally Fair.com? An Update on Bias Allegations and the ICANN UDRP. University of Ottwa, 2002b. 
GILWIT, Dara B.The Latest Cybersquatting Trend:Typosquatters, Their Changing Tactics, and How to Prevent Public Deception and Trademark Infringement. Washington University Journal of Law \& Policy, Washington, v. 11, n. 1, p. 267-294, jan. 2003. Disponível em: https://openscholarship.wustl.edu/cgi/viewcontent. cgi?referer=\&httpsredir=1\&article=1326\&context=law_journal_law_policy. Acesso em: 12 jun. 2020.

HELFER, Laurence R. International Dispute Settlement at the Trademark-Domain Name Interface. Pepperdine Law Review, Malibu, v. 29, n. 1, p. 87-99, 2001. Disponível em: https://ssrn.com/abstract= 265922. Acesso em: 12 jun. 2020.

HESTERMEYER, Holger P. The Invalidity of ICANN's UDRP under National Law. Minnesota Intellectual Property Review, v. 3, n. 1, 2002. Disponível em: https:/ / bit.ly/3yjU3mA. Acesso em: 31 jul. 2021.

HOLMAN, Robert. Economic Analysis of Law. Politická ekonomie, v. 52, n. 4, p. 519-531, 2004. Disponível em: https://polek.vse.cz/artkey/pol-200404-0005_ekonomicka-analyza-prava.php. Acesso em: 3 ago. 2021.

HYLTON, Keith N. Law and Economics Versus Economic Analysis of Law. European Journal of Law and Economics, v. 48, p. 77-88, 2019.

INTERNET CORPORATION FOR ASSIGNED NAMES AND NUMBERS (ICANN). Política para resolução uniforme de litígios sobre nome de domínio. ICANN Webpage, 24 out. 1999. Disponível em: https://www.icann.org/resources/pages/policy-2012-02-25-pt. Acesso em: 21 mar. 2020.

INTERNET CORPORATION FOR ASSIGNED NAMES AND NUMBERS (ICANN). Beginner's Guide to Domain Names. Los Angeles: ICANN Publishing, 2010. Disponível em: https://www.icann.org/en/ system/files / files/domain-names-beginners-guide-06dec10-en.pdf. Acesso em: 12 nov. 2019.

INTERNET CORPORATION FOR ASSIGNED NAMES AND NUMBERS (ICANN). Regras para a política uniforme de resolução de conflitos com nomes de domínio. ICANN Webpage, 2013. Disponível em: https://www.icann.org/resources/pages/udrp-rules-2015-03-13-pt. Acesso em: 25 abr. 2020.

JUNGMANN, Diana de Mello. A caminho da inovação: proteção e negócios com bens de propriedade intelectual: guia para o empresário. Brasília: IEL, 2010.

KAPLOW, Louis; SHAVELL, Steven. Economic Analysis of Law. In: AUERBACH, Alan J.; FELDSTEIN, Martin. Handbook of Public Economics. Amsterdã: Elsevier, 2002. v. 3.

KING, Stacey H. The Law That It Deems Applicable: ICANN, Dispute Resolution, and the Problem of Cybersquatting. Hastings Communications and Entertainment Law Journal, São Francisco, v. 22, n. 3. p. 453-508, 
2000. Disponível em: https://repository.uchastings.edu/hastings_comm_ent_law_journal/vol22/iss3/4. Acesso em: 12 jun. 2020.

KRUGER, Lennard G. Internet Domain Names: Background and Policy Issues. Washington: Congressional Research Service Report, 6 mar. 2015. Disponível em: https://fas.org/sgp/crs/misc/97-868.pdf. Acesso em: 15 nov. 2019.

LANDES, William M.; POSNER, Richard A. An Economic Analysis of Copyright Law. The Journal of Legal Studies, Chicago, v. 18, n. 2, p. 325-363, jun. 1989. Disponível em https://www.sfu.ca/ allen/ copyright.pdf. Acesso em: 12 jun. 2020.

LANDES, William M.; POSNER, Richard A. The Economic Structure of Intellectual Property Law. Cambridge: Harvard University Press, 2003.

MANKIW, N. Gregory. Introdução à economia. 8. ed. Tradução Allan Vidigal Hastings, Elisete Paes e Lima, Ez2Translate. Revisão técnica: Manuel José Nunes Pinto. São Paulo: Cengage, 2020.

MENELL, Peter S. Intellectual Property: General Theories. In: BOUCKAERT, Boudewijn; DE GEEST, Gerrit (eds.). Encyclopedia of Law and Economics. v. 2. Cheltenham: Edward Elgar, 2000. p. 129-188.

ORGANIZAÇÃO MUNDIAL DA PROPRIEDADE INTELECTUAL (OMPI). Understanding Industrial Property. 2. ed. Genebra: OMPI, 2016. Disponível em: https://www.wipo.int/edocs/pubdocs/en/wipo_ pub_895_2016.pdf. Acesso em: 16 nov. 2019.

\section{ORGANIZAÇÃO PARA A COOPERAÇÃO E DESENVOLVIMENTO ECONÔMICO (OCDE).} Generic Top Level Domain Names: Market Development and Allocation Issues. Paris: Working Party on Telecommunication and Information Services Policies Paper, 13 jul. 2004. Disponível em: www.oecd. org/internet/ieconomy/32996948.pdf. Acesso em: 13 nov. 2019.

POPOVIĆ, Duśan. Internet Domain Names: Administration of Domain Names and Dispute Resolution. In: POPOVIĆ, Duśan; NAUMOVSKI, Goce. Information Technology Law, Escópia, 2011. Disponível em: https://bit.ly/3ok9M2y. Acesso em: 2 dez. 2021.

SILVEIRA, Newton. Propriedade intelectual: propriedade industrial, direito de autor, software, cultivares, nome empresarial, abuso de patentes. 5. ed. Barueri: Manole, 2014.

TANENBAUM, Andrew S. Redes de computadores. 4. ed. Tradução Vandenberg D. de Souza. Rio de Janeiro: Campus, 2007. 
VASCONCELOS, Claudio Lins de. Mídia e propriedade intelectual: a crônica de um modelo em transformação. Rio de Janeiro: Editora Lumen Juris, 2010.

\section{COMO CITAR ESTE ARTIGO:}

CASTRO, Carla Frade de Paula et al. Nomes de domínio e propriedade intelectual: reflexões sobre resolução de controvérsias a partir da Análise Econômica do Direito. Revista Direito GV, São Paulo, v. 18, n. 1, jan./abr. 2022, e2208. https://doi.org/10.1590/23176172202208
Carla Frade de Paula Castro

Bacharela em Direito, especialista em Relações INTERNACIONAIS E MESTRA EM PROPRIEDADE INTELECTUAL E TRANSFERÊNCIA DE TECNOLOGIA PARA A INOVAÇÃO PELA UNIVERSIDADE DE BRASÍLIA (UNB). carlafpclagmail.com

Davi Antonio Araújo Silva

EngenheIRo de Redes de Comunicação PELA Universidade dE Brasília (UnB). Especialista em Gestão de TI PELA UnB. BACHAREL EM DiREITO PELA UNB. engdaviaraujolagmail.com

\section{Gabriel Araújo Souto}

Estudante visitante do LLM de Global Antitrust LaW \& Economics (ANTONIn Scalia LaW School of GEorge Mason UNIVERSITY, 2018). BACHARELANDO EM DIREITO PELO INSTITUTO Brasileiro de Ensino, Desenvolvimento e Pesquisa (IDP).

gasoutodoutlook.com

Nayara F. Macedo de Medeiros Albrecht

Doutora em Ciência Política pela Universidade de Brasília (UnB). Pesquisadora de Pós-doutorado na Universidade de SÃo Carlos e bolsista da FAPESP (PROCESSO N. 2019/19570-8).

nayara.albrechtagmail.com 